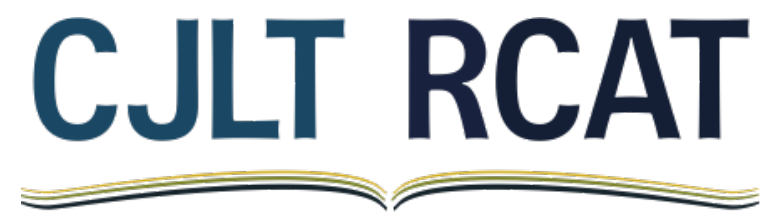

Canadian Journal of Learning and Technology

La Revue canadienne de l'apprentissage et de la technologie

Volume $46(3)$

Fall/Automne 2020

\title{
MOOCs and Open Education in the Global South: A Review
}

\author{
Christopher J. Devers, Johns Hopkins University, Lumen Research Institute
}

\section{Overview}

This timely and eye-opening book from Ke Zhang, Curt Bonk, Tom Reeves, and Tom Reynolds, MOOCs and Open Education in the Global South (Zhang, Bonk, Reeves, \& Reynolds, 2020), provides 28 chapters that describe the challenges, successes, and opportunities of MOOCs and open education from the perspective of 68 authors from 47 countries in the Global South (http://moocsbook.com). Before those chapters, a detailed preface from the four editors lays out the journey that the world community took to get to this point in the metaphor of a wanderer who makes his or her path by pushing ahead and exploring the road in front. In addition, an insightful foreword is provided by Mimi Miyoung Lee from the University of Houston who had previously co-edited an award-winning book with Bonk, Reeves, and Reynolds; namely, MOOCs and Open Education Around the World (Bonk, Lee, Reeves, \& Reynolds, 2015). Thus, consider the current book Part 2 of what is likely to become a many act play in the world of MOOCs and open education. With the foreword and preface, there are 30 pieces in total (Note: the front matter is available for free from: http://moocsbook.com/MOOCs_Open-Ed_GlobalSouth-frontmatter_2020_Zhang_Bonk_Reeves_Reynolds.pdf).

Specifically, the chapters of this new MOOCs and open education volume span immense geographic boundaries such as Africa, Asia, Latin America, the Caribbean, Middle East, and the Pacific. The seven sections of the book cover historical perspectives, current practices and designs, MOOCs and open education for professional development, multi-country collaboration and collections, government policy and strategies, organizational innovations, and the future of MOOCs and open education. Readers will appreciate the diversity of countries and topics discussed. A few recurrent themes present throughout the book include the sensitivity that MOOCs and open education need in addressing local and cultural contexts and pedagogical practices, the strong governmental and local policy required to support MOOC and open education development, and the need to address the requirements of low bandwidth and mobile users.

\section{Historical Perspectives}

Both historical chapters in the book offer unique insights into their respective countries -- Korea and China. While MOOCs are relatively young, as arguably the first MOOC was offered by Stephen Downes and George Siemens in 2008 with about 2,300 students, MOOCs have deep roots in the open 
education movement. For example, while not directly labeled a MOOC, many students participated in large open educational initiatives, such as Korean Open Course Ware (KOCW). Currently in Korea, the government has invested heavily in the development of K-MOOCs, which have about 22.8 million registered users, 600+ lectures, paid services, and many university partners. Similar to Korea, China too has experienced a large increase in MOOC development from the government and universities. For example, in 2018, the Korean Ministry of Education introduced 490 National Elaborate Online Courses, which grew to over 2000 in 2020. With the explosion of MOOCs in both countries, there are a variety of platforms that offer MOOCs and research opportunities. As MOOCs move forward, it will be important to consider how to use experimental research to explore ways to increase learning and engagement in MOOCs, in an attempt to increase course quality and student success.

\section{Current Practices and Designs}

The section on Current Practices and Designs, consists of eight chapters that explore MOOCs from Egypt, Indonesia, Sri Lanka, Fiji, Nepal, and Latin America. The section starts with a discussion about openness -- cultural, technical, pedagogical, legal, and financial. Like the two historical chapters, much of the MOOCs and open educational resources are supported by multiple organizations and governments. For example, the Arab League Educational, Cultural, and Scientific Organization (ALECSO) promotes open and accessible online learning opportunities for 22 Arab countries. Additionally, Egypt has developed a set of open educational practices that help support online and open content specifically for the region. Next the section outlines risks to consider when designing open educational environments -- textbook cost, the digital divide, voluntary labor, accessibility, and privacy.

While Indonesia is the fourth largest country by population, the number of country-specific MOOC providers is small (about five) with just over 100 courses offered. Chapter 7 from Som Naidu in Fiji and Shironica Karunanayaka in Sri Lanka focuses on thinking about learning outcomes and the learner. Specifically, it explores design considerations for creating MOOCs that provide local contextualized real-world problem solving. Next, in Chapter 8, Deepak Bhartu from the Centre for Flexible Learning at the University of the South Pacific joins Naidu to argue that much of the world does not have high bandwidth access, and, therefore, MOOCs should consider creating low bandwidth options. Both in 2015 and 2017, a climate change MOOC was offered for the Pacific Islands region with a completion rate of $26 \%$ and $39 \%$ respectively.

While the Pacific Islands region does not appear to have as large enrollments as other areas, it is possible, based on past data, that many who sign up complete the course. One area that is often overlooked is the impact that MOOCs have in K-12 education. As detailed in Chapter 9 from Baman Ghimire and Bishwa Gaitam, when resources are limited, such as they are in Nepal, MOOCs can offer opportunities that are not often available or are lacking in many K-12 environments. Chapter 10 from Jaime Sanchez and Jose Reyes-Rojas suggest that strong data on MOOCs in Latin America are also lacking. For example, between 2014 and 2019 only 24 articles were found that met the authors' selection criteria in Chapter 10. Last, Trang Phan in Chapter 11 describes the experiences of 15 MOOC instructors and the importance of cultural contexts and sensitivity when teaching students from across the globe, and specifically the Global South. As MOOCs and open education evolve, it will be increasingly important to consider how to localize the context for students and assignments and to take bandwidth into consideration. 


\section{MOOCs and Open Education for Professional Development}

The section on professional development describes how MOOCs have been important in helping upskill and reskill workers. As with other Global South MOOCs, the participant numbers are not as large as in the Global North; for example, Belawati in Chapter 6 suggests that many of the MOOCs in Indonesia have less then 1,000 participants. However, preliminary data suggests that targeted MOOCs, like professional development, often have higher completion rates. Next, the section describes the current landscape of MOOCs and open education in Thailand, as well as its future directions. Like many similar developing countries, the government of Thailand provides support for MOOCs and open education as an avenue to increase education and economic growth. Using a research-based approach, Thailand created a strong educational network to support MOOCs and open educational opportunities and has created a 2018-2022 strategic plan to strengthen its open education initiatives.

One method to improve student learning, engagement, and retention is to increase instructor quality through professional development training. In collaboration with Athabasca University and the Commonwealth of Learning, Chapter 14 describes a MOOC that was created to provide professional development for instructors. Specifically, the course covered models of learning, technology in education, open educational resources, applications of technology, and creating technology-supported learning, and had just over 5,000 participants. The last chapter of the section, Chapter 15, details the creation and implementation of a South African MOOC designed to provide a place to discuss and learn about specific issues in the African region, as well as create possible solutions. One impact of offering the MOOC was increasing the opportunity to breakdown silos, work together, and offer unique solutions to complex issues in Africa with others from around the world, both within the MOOC itself and from the process of creating it. As developing countries consider creating open educational content, it is likely that creating specific professional development opportunities that are localized to the region will provide students with needed reskilling and upskilling opportunities.

\section{Multi-Country Collaboration and Collections}

MOOCs and open education are by nature collaborative; however, structure and focus can help support continued collaboration after the course ends. The first chapter in this section, "Courses for a Cause," describes the impact that targeted MOOCs have on students and the local community. Specifically, the MOOC described in this chapter was built upon equity, the wicked problem of sustainability, and action for the public well-being, in an effort to spark global and collaborative sustainability actions. The following chapter, led by Insung Jung of International Christian University in Japan, explores MOOCs in six developing countries (e.g., Indonesia, Malaysia, Mexico, the Philippines, Thailand, and Vietnam) and what resources were needed to support them. Most MOOCs in these countries were developed later then MOOCs in America, and many were eventually supported by the government -- some governments even created strategic plans to develop and support open education. As MOOCs continue to evolve, providing government support earlier will likely aid in the initial development of the MOOC, establish the legitimacy of it, and contribute to its sustainability.

Last, this section explores the impact MOOCs are having in Latin America and the Caribbean (LAC) from the perspective of the Inter-American Development Bank. Many of the top MOOCs in the LAC region deal with economic development -- project management, city development, policymaking, management, and social development. Students described that participation in economic developmentrelated MOOCs had a positive impact on their academic endeavors, professional skills, workplace 
environment, and social lives. In order to support continued action, open content developers should consider creating learning opportunities around localized problems that utilize ideas from both local experts, as well as experts from around the globe.

\section{Government Policy and Strategies}

As discussed in the previous sections, many of the initiatives regarding MOOC development started small with little support and later developed into strong open educational initiatives supported by the government. For example, as detailed in Chapter 19, in Brazil, over 100 universities make up the Open University of Brazil (UAB), which provides educational opportunities to populations that traditional institutions are unable to serve. A recent survey from faculty/staff that were involved in the UAB suggests that there is room for participating institutions to develop stronger open educational polices, training, support, and incentives for creating/using open resources.

Chapter 20 shifts the reader to MOOC policy in Malaysia. In an effort to support open education, the Malaysian government created a strategic plan for $2015-2025$, with a goal of $30 \%$ of all public university courses to be offered as a MOOC by 2020. However, such a plan requires strong policy, support, and investment in sustainability. Specifically, in order for MOOCs to be successful in Malaysia, MOOCs need to support student needs and employ strong evidence-based practices when engaging and teaching large numbers of students.

Next in Chapter 21, Melinda dela Pena Bandalaria explains that in an effort to support open education and MOOC development in the Philippines, the Open Educational Resources for Development Framework (OER4D) was created and driven by two fundamental ideas. First, open content should positively impact instruction and support equality in learning. Second, the content should support MOOCs relevant to the needs of the people of the Philippines. Using these two ideas as a framework provided much needed guidance, development, and support when planning and implementing MOOCs and open educational resources for the Filipino community.

Online education, specifically MOOCs, have the potential to greatly impact the Middle East because traditional education presents difficult challenges for many learners. As MOOCs evolve, developing support for local contexts and student needs will be helpful according to Abtar Darshan Singh and her colleagues in Chapter 22. For example, creating assignments that present real issues and address adaptive, personalized, and immersive learning needs are vital for MOOC success. There is also a need to support shorter courses through micro-credentials provided through one's native language; such localization approaches provide contextual and personalized learning experiences for students. Additionally, as MOOCs evolve, support for universities to offer them and provide accreditation will help legitimize the courses, especially for those students for whom traditional education is not a feasible option. When laying the foundation for educational innovations like MOOCs, leaders should consider policy, but it will also require strong strategic plans, both governmental and local, to help drive the policy and implementation forward.

\section{Organizational Innovations}

The World Bank is a leader in open educational resources and MOOCs. As Sheila Jagannathan lays out in Chapter 23, they play an important role in social and developmental change. Specifically, the 
World Bank uses the United Nations 17 Sustainable Development Goals (SDGs) when developing open educational initiatives. In an effort to support the SDGs and change policy, institutions, business, individuals, and behavior, the World Bank uses three distinct open educational components that make up their Open Learning Campus (OLC). These three components (i.e., WB Talks, WB Academy, and WB Connect) provide the essential content and social connection with others, in an effort to create sustained global change. As described by the World Bank, Sub-Saharan Africa and South Asia account for a particularly large number of the world's poor and could greatly benefit from open education initiatives and mobile learning.

According to Atieno Adala in Chapter 24, the African Virtual University (AVU) is a select group of universities in Africa that support an innovative math and science teacher training program that exclusively uses open educational resources. Even though the AVU created the material, there were unforeseen issues with the adoption of it. For open educational practices to be successful, institutions like the AVU need to adopt supportive polices.

Given that many developing countries, like India, lack foundational infrastructure, in Chapter 25 we find out that MOOCs can provide essential educational opportunities for anyone with a mobile device. For example, during 2017-2018 nearly 50\% of the participants in the agricultural MOOC (AgMOOC) accessed it using a mobile device. As high-speed mobile Internet connections become more prevalent in developing countries, it will be increasingly important to consider mobile educational options.

Additionally, as developing counties ramp up open educational opportunities, it is likely that some students will need support as education moves from face-to-face to online. As discussed in Chapter 26, in Kenya, for example, many students lacked the skills needed to be successful in online education, and therefore, an organization offered onboarding face-to-face training sessions for students that covered teamwork, a variety of software packages, self-regulation strategies, etc. An unseen advantage of offering the onboarding was that when technical problems occurred in the training, like loss of Internet, teams worked together to find solutions, much like they would need to in the online environment. Working closely with organizations like the World Bank, the United Nations, and other consortiums, developing countries can take advantage of lessons learned by others, borrow content, and receive guidance, in an effort to overcome obstacles that are associated with creating MOOCs and open educational content.

\section{The Future of MOOCs and Open Education}

Artificial intelligence (AI) and big data have the potential to support student learning and engagement in unique ways. While clearly AI is still in its beginning stages, as Paul Kim and Jieun Lee point out in Chapter 27, there are current systems that are exploring how it can be used for personized adaptive learning and student support. For example, there are AI systems that can provide support using a chatbot, act as a teaching assistant, flag at-risk students in an effort to decrease the achievement gap, assess assignments, personalize content, and even offer counseling services. These types of services could prove very valuable when dealing with MOOCs that have thousands of students enrolled.

Combined together, these types of AI support systems offer powerful tools to help the students succeed, stay engaged, and increase learning. As open education and MOOCs evolve and AI provides instructor and student support, it is likely that MOOCs will become interwoven into current educational 
programs, offered as standalone micro/mini degrees, better support mobile and low bandwidth, provide reskilling and upskilling for workers, provide free and reduced cost certifications and degrees, and become foundational in developing countries where traditional education is not feasible.

\section{Strengths}

First, the book provides strong arguments and support for the need for MOOCs and open education that addresses the local and cultural needs of the community (Laurillard \& Kennedy, 2017). The readers will appreciate the amount of detail that the chapters provide, as they offer a strong roadmap for how to localize MOOCs and open education. Second, for organizations wanting to engage in developing open content, the authors address and describe in detail the need for strong government and local support (Kanwar, Kodhandaraman, \& Umar, 2010). Without both government and local support, it is likely that open content will not be embraced by the population, and therefore be underutilized. Last, the book addresses and describes the importance of creating content that can be accessed over low bandwidth or intermittent Internet access (Alcorn, Christensen, \& Kapur, 2015; King, Pegrum, \& Forsey, 2018). Again, if open content is not able to be accessed, it will not be used. Given the vast amount of detail that covers a wide range of geography in the Global South, readers who are interested in, or plan on implementing open content, will gain valuable insight from those who have gone before them and detailed their accounts in this book.

\section{Weaknesses}

While the book has many strengths, there are some weaknesses. First, given the breadth of MOOCs and open education in the Global South, to fully grasp the impact, the book would likely need an additional 30-40 chapters, and a larger selection from Africa. Second, the book would be stronger if the chapter authors communicated, in an effort to connect chapters together and create a unified approach. Third, the book is relatively expensive, especially given that those from the Global South would benefit from the content. Last, while books are beneficial, they are often outdated when they are released, given the length of the editing and publishing process. Regardless of the weaknesses, readers will still appreciate and learn much from the detailed accounts of MOOCs and open education in the Global South.

\section{Concluding Thoughts}

Overall, the book reads like a series of small case studies (Stake, 1995; Yin, 2003) that describe the challenges, successes, and opportunities of MOOCs and open education in the Global South. Many readers will find these case studies beneficial when thinking about developing their own content. Specifically, as educational content becomes increasingly available, it is clear that localized and contextual practices will serve the community well. However, it is likely that for MOOCs to be successful, they will require strong governmental and local support, while also developing support for low bandwidth and mobile users. Additionally, it would be helpful for faculty and students, if there were a central location that listed regional and localized MOOCs and open educational content -- such a database would connect faculty to relevant local open course material, as well as connect students to course providers. This brilliant and comprehensive book from Zhang, Bonk, Reeves, and Reynolds offers a solid foundation for those interested in learning more about MOOCs and open educational content. It also provides a roadmap for developers creating courses and content to help address regional 
and local community needs in developing countries as well as for those in the midst of wandering in this wonderful world of MOOCs and open education. 


\section{References}

Alcorn, B., Christensen, G., \& Kapur, D. (2015). Higher Education and MOOCs in India and the Global South. Change: The Magazine of Higher Learning, 47(3), 42-49. https://doi.org/10.1080/00091383.2015.1040710

Bonk, C. J., Lee, M. M., Reeves, T. C., \& Reynolds, T. H. (Eds.). (2015). MOOCs and open education around the world. NY: Routledge.

Kanwar, A., Kodhandaraman, B., \& Umar, A. (2010). Toward Sustainable Open Education Resources: A Perspective From the Global South. American Journal of Distance Education, 24(2), 65-80. https://doi.org/10.1080/08923641003696588

King, M., Pegrum, M., \& Forsey, M. (2018). MOOCs and OER in the Global South: Problems and Potential. The International Review of Research in Open and Distributed Learning, 19(5). https://doi.org/10.19173/irrodl.v19i5.3742

Laurillard, D., \& Kennedy, E. (2017). The potential of MOOCs for learning at scale in the Global South. Center for Global Higher Education, 13.

Stake, R. (1995). The art of case study research. Thousand Oaks, CA: Sage Publications.

Yin, R. (2003). Case study research: Design and methods (3rd ed. Vol. 5). Thousand Oaks: Sage Publications.

Zhang, K., Bonk, C. J., Reeves, T. C., \& Reynolds, T. H. (Eds.). (2020). MOOCs and open education in the Global South: Challenges, successes, and opportunities. NY: Routledge. 


\section{Author}

Christopher Devers received a Ph.D. in curriculum and instruction from the University of Illinois, as well as a MS in educational administration and a BS in engineering and technology education from Purdue University. He is an Assistant Professor at Johns Hopkins University and a Senior Fellow at Lumen Research Institute. http://orcid.org/0000-0003-0748-918X.

Email: christopherdevers@gmail.com

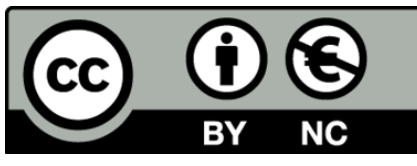

This work is licensed under a Creative Commons Attribution-NonCommercial CC-BY-NC 4.0 International license. 